\title{
T. Соколова
}

\section{ЕВРАЗИЙСКАЯ ИНТЕГРАЦИЯ: СОЦИАЛЬНЫЙ АСПЕКТ}

DOI: $10.20542 / 2073-4786-2019-3-27-42$

\section{Социокультурные факторы евразийской интеграции}

Поиск причин «пробуксовки» социально-экономической трансформации и интеграции на евразийском пространстве в категориях геополитики и геоэкономики не увенчался успехом, поскольку распад СССР привел в движение мощные социокультурные и ментальные пласты, обусловил центробежные тенденции в масштабах некогда единой культурно-исторической общности. Ожидания быстрой отдачи от, казалось бы, «достаточно высокого потенциала естественной солидарности населяющих регион народов, которая проистекает из их многовекового совместного проживания, этнокультурного и экономического взаимодействия и встречных миграционных движений» [1, с. 3-4] оказались чрезмерно завышенными.

По логике, «снижение барьеров на пути товаров, услуг, людей и капиталов по мере углубления интеграции должно способствовать развитию взаимных торговых и инвестиционных связей и, тем самым, способствовать росту экономики регионов. Но практика постсоветских интеграционных проектов этого не подтверждает» [2, с. 31]. С одной стороны, «унаследованные от СССР общие черты и связи создают иллюзию легкости реинтеграционных процессов на нашем пространстве». С другой - «задача реинтеграции пространства оказывается много сложнее, чем формирование европейской интеграции с нуля. Прошлый опыт способен оказывать значительно более негативное влияние, нежели отсутствие опыта совместной жизни, как такового» [3, с. 81].

Чрезвычайно важное значение имеет «...отношение и интерес общества к интеграционному проекту. Это задает общий положительный фон и во многом определяет динамику» [4, с. 96]. Однако проект ЕАЭС в значительной мере находится на периферии внимания СМИ стран участниц Союза. Интеграционная повестка имеет лишь косвенное отношение к повседневной жизни людей и поэтому воспринимается ими как нечто «виртуальное» [5, с. 5]. Все это сказывается на ходе интеграционных процессов на постсоветском пространстве, их противоречивом и разнонаправленном характере. Кроме того, по мнению академика 
В.Полтеровича, «если в программе реформ не учтены существующие ресурсные, технологические, институциональные и культурные ограничения, то законодательно внедренные институты оказываются дисфункциональными» [6, с. 17-18].

Неслучайно в научном и экспертном дискурсе все чаще затрагиваются вопросы социокультурной составляющей интеграционных процессов. Так, эксперты Евразийского банка развития считают, что «успех евразийской интеграции по-прежнему будет во многом зависеть и от усилий, направленных на повышение долгосрочной устойчивости евразийского интеграционного проекта, его привлекательности не только в экономическом и военно-политическом плане, но и в научнообразовательном, культурном и общем гуманитарном аспектах» [7, с. 25].

Игнорирование социального фактора существенно снижает прочность интеграционных связей, ставит под угрозу эффективное интеграционное взаимодействие и «..даже серьезные политические договоренности и взаимозависимость национальных экономик не спасают от дезинтеграции при разрыве гуманитарной (культурной) связи и информационно-идеологическом противостоянии» [8, с. 18]. А.Крылов и А.Арешев отмечают, что «...евразийская интеграция имеет много измерений и отнюдь не исчерпывается экономическим прагматизмом. Социальная, политическая, культурно-цивилизационная составляющие играют не менее важную роль в успешной реализации интеграционного проекта» [9, с. 25].

В ряде научных трудов Института экономики РАН, посвященных интеграционной проблематике, прослеживаются схожие позиции. Так, Л.Зевин подчеркивает, что «... региональная интеграция не является чисто экономическим процессом... [Старт интеграции] становится возможным при наличии поддержки значительной части общества будущих партнеров (социальный фактор); ...мотивация к объединению опирается на исторический опыт общения и культурно-цивилизационные связи...» $[10$, с. 20]. Л.Вардомский утверждает, что именно социокультурные приоритеты становятся критически важными при выборе постсоветскими странами вектора интеграции: «...речь идет о выборе между присоединением к европейской интеграции, созданием своего евразийского объединения или проведением многовекторной внешней политики» [11, с. 104].

Авторы коллективного научного доклада «Евразийский интеграционный проект: эффекты и проблемы реализации» полагают, что «важнейшую роль в углублении интеграции могли бы сыграть социальные и культурные факторы. ...Использование культурных факторов более чем оправданно в интеграционном строительстве в силу взаимопроникновения культурных традиций на протяжении многих десятилетий совместного проживания народов», и приходят к выводу, что «вопросы развития 
социальной сферы, выравнивания региональных и структурных диспропорций должны стать важной составляющей социальноэкономической политики Евразийского экономического союза» [3, с. 87-88]. По мнению Л.Косиковой, социальные факторы призваны сыграть «цементирующую» роль в процессе успешной региональной интеграции: «...социальный фактор в процессе региональной интеграции чрезвычайно важен, как один из главных “скрепов" межгосударственных союзов, создающий стимулы к сближению именно “снизу”, со стороны населения сотрудничающих государств» [12, с. 18, 22-23].

Очевидно, сфера взаимодействия населения постсоветского пространства в сфере культуры, искусства, образования, спорта, туризма, а также личных (в том числе профессиональных, родственных и т.п.) связей изначально обладает мощным интеграционным потенциалом. Детальное исследование социокультурного (гуманитарного) притяжения стран постсоветского пространства регулярно проводится в рамках проекта «Интеграционный барометр ЕАБР», реализуемого Центром интеграционных исследований Евразийского банка развития и Международным исследовательским агентством «Евразийский монитор».

В 2017 г. для государств - членов ЕАЭС и Таджикистана была характерна чрезвычайно высокая плотность взаимных социальных связей за исключением России, более 50\% граждан заявили о наличии постоянно поддерживаемых связей с родственниками, друзьями, коллегами из стран региона СНГ. Наиболее высокие показатели были зафиксированы в Киргизии (80\%), Армении (79\%) и Таджикистане (66\%). В РФ лишь 31\% населения поддерживает постоянные социальные связи в соседних по региону СНГ странах, а большинство (61\%) не поддерживает их вообще [8, с. $15]$.

Наибольший взаимный интерес закономерно проявляют жители двух славянских государств - России и Белоруссии, а также Казахстана. В силу особенностей своего социокультурного профиля Казахстан занимает промежуточное положение между «восточным» и «западным» векторами интеграционных предпочтений. Вместе с тем широкое распространение традиционных институтов родственно-семейных связей в хозяйственных практиках, коллективистская культура и распространение традиционных ценностей (религия, семья) в наибольшей степени способствуют сближению Казахстана именно с Россией и Белоруссией.

Самой близкой к России является базовая культурная идентификация Белоруссии. На вопрос: «Вы считаете себя более близким к русским или к европейцам?» почти три четверти белорусских респондентов отвечают «к русским», и лишь около $20 \%$ - «к европейцам», объясняя это прежде всего историческими $(49,5 \%)$, культурными $\quad(39,9 \%)$ и языковыми $(36,2 \%)$ 
причинами [13, с. 29]. В условиях состоявшегося политического «развода» России и Украины сейчас именно на долю Белоруссии выпала особая миссия по формированию зоны объединения Евразии [11, с. 107].

Четко выраженный вектор социокультурного притяжения на постсоветском пространстве образует и сохраняющийся интерес населения стран Центральной Азии к РФ, несмотря на то что в Узбекистане, Туркмении и Таджикистане проявляется тяготение и к странам арабского, персидского и тюркского национально-культурных кластеров.

Гораздо более противоречивы в проявлениях своих социокультурных предпочтений государства Южного Кавказа. Принципиальное отличие этого региона от других частей постсоветского пространства состоит в том, что он всегда чисто «исторически существовал как регион с подвижными границами, различными государственными, этническими и конфессиональными идентичностями» [14, с. 36]. До сих пор тлеющие региональные конфликты на спорных территориях (Нагорный Карабах, Южная Осетия, Абхазия) ощутимо нарушают и без того хрупкий баланс социально-политического равновесия в Азербайджане, Армении и Грузии.

Самый острый камень преткновения - Нагорный Карабах. Являясь ключевым компонентом как армянской, так и азербайджанской национальной идентичности, он превратился в «яблоко раздора» как с этнополитической, так и с оборонной точек зрения [15]. Кроме того, на Южный Кавказ приходится половина (четыре из восьми) всех вооруженных конфликтов на постсоветском пространстве - армяно-азербайджанский, грузино-абхазский, грузино-осетинский, а также внутригрузинская гражданская война. Все эти «болевые точки», буквально пронизывающие пространство Южного Кавказа, придали отношениям государств-соседей дополнительный центробежный импульс, который существенно затруднил процессы социально-экономической трансформации Южного Кавказа.

Показательно, что ни одна из стран этого региона не считает своих непосредственных соседей друзьями. Для подавляющей части населения Азербайджана (91\%) - это Турция, для Грузии (49\%) - США и Дания. Население Армении (63\%) ставит на первое место (и с большим отрывом) Россию [16]. Вместе с тем особое значение в сотрудничестве Грузии и Армении имеет их культурно-конфессиональная общность. В этих условиях для России наиболее целесообразным представляется наращивание экономических и гуманитарных связей со всеми странами Южного Кавказа, независимо от их текущих интеграционных предпочтений [17, с. 62-67], но с обязательным учетом их социокультурных и ментальных особенностей.

В 2017 г. внутри региона СНГ отмечен высокий взаимный интерес государств к продукции культурной индустрии - кинематографу, литературе, музыкальному искусству. Среди лидеров - Таджикистан (69\%), Казахстан 
(68\%) и Белоруссия (60\%), самый низкий показатель - в Армении (36\%) [8, c. 16]. К сожалению, подобные гуманитарные скрепы «снизу» в течение длительного времени не получали должной поддержки на официальном законодательном уровне. Лишь в 2006 г. (по прошествии 15 лет с момента распада СССР) были созданы Совет по гуманитарному сотрудничеству (СГС) и Межгосударственный фонд гуманитарного сотрудничества государств - участников СНГ (МФГС). В середине 2011 г. принята Концепция развития образования в сфере культуры и искусства государств участников СНГ. По мнению Д.Ушкаловой и М.Головнина, чрезмерное увлечение экономическими теориями интеграции не могло не сказаться на эффективности попыток объединения [18, с. 37-38].

Кроме того, «идеологический шок начала 90-х гг., следствием которого стало разрушение советской идентичности многих представителей старших поколений и утрата смысла прожитой ими жизни, привел к социальной, этнической и психологической дискриминации носителей советской ментальности на всем постсоветском пространстве» [19, с. 35]. В связи с этим запустить процесс евразийской интеграции, опираясь только на разрозненные национальные идентичности, так и не удалось. Возможно, во многом именно поэтому «Евразийский экономический союз, при всей его практической полезности, не стал центром силы в Евразии» [20].

В последние годы практически во всех странах общественная поддержка ЕАЭС постепенно снижалась. Высокий уровень одобрения членства в ЕАЭС, зафиксированный в 2015 г., был, скорее всего, своего рода авансом общественного доверия, связанного с позитивными ожиданиями. Вместе с тем неблагоприятная внешняя конъюнктура, в условиях которой зарождалось и развивается новое интеграционное объединение (мировой экономический кризис, межгосударственные конфликты в регионе СНГ), не позволяет реализовать ожидания скорых положительных эффектов интеграции, и это ведет в том числе к отрицательной динамике общественных настроений.

Так, в Молдове впервые за шесть лет исследований «Интеграционного барометра ЕАБР» общий индекс притяжения к Евросоюзу стал выше аналогичного индекса притяжения к региону СНГ. Небольшая отрицательная динамика притяжения в целом ко всем странам региона СНГ зафиксирована в Армении (по отношению к России значительная). В Таджикистане и Молдове также значительно снизилось притяжение к РФ. При этом интеграционное позиционирование самой России по-прежнему многовекторно. В предпочтениях россиян примерно в равной степени присутствуют все геополитические векторы (страны региона СНГ, ЕС и «остального мира») [8, с. 20-22]. 
В ходе постсоветской трансформации постепенно утрачивались и потребность в знании русского языка как языка межнационального общения, и понимание культуры других народов, населявших некогда единую страну [21; 22]. Русскоговорящая часть населения медленно перемещалась в двуязычную категорию, когда русский и титульный языки в повседневном общении используются в равной степени. За счет этого удалось компенсировать стремительное сокращение (в ряде случаев вплоть до полного запрета) использования русского языка как единственного. Представителей русскоязычной среды стало меньше на $15 \%$ в Узбекистане и на $82 \%$ в Таджикистане [23, с. 42].

За истекшие четверть века в новых независимых государствах выросло поколение, которое вместе с теми, кто в момент распада СССР были еще детьми, является носителем менталитета, принципиально отличного от советского. И это каждый пятый (около 60 млн. человек в возрасте от 15 до 29 лет) из более чем 280 млн. человек, проживающих в СНГ. В среднем доля молодежи составляет от 18 до 29\% всего населения [24, с. 15]. Молодое постсоветское поколение не имеет опыта проживания в большой объединенной стране, восприятие которой формируется только на основе внешних интерпретаций.

По данным социологических опросов, отношение к СССР существенно дифференцировано в разных возрастных группах (чем моложе, тем отношение хуже или безразличнее). Особенно стремительно размывается «советская идентичность» в странах Центральной Азии, где более половины населения составляет молодежь до 30 лет, получившая среднее образование в рамках национальной школьной системы и не испытавшая непосредственного влияния общих «советских» ценностей. Как отмечают эксперты из Казахстана, «если первые 25 лет независимого развития Центральная Азия находилась в фарватере постсоветской инерции (экономические модели, элиты и их видение мира, образование, социальный уклад и др.), то, по всей вероятности, нарождающиеся в настоящее время глобальные мегатренды и новое, последовательно набирающее силу поколение (со своими взглядами, ценностями, устремлениями и др.) обусловят для нашего региона начало совершенно нового исторического этапа» [25, с. 26, 76].

Таким образом, ностальгия и позитивное отношение к общей истории все в меньшей степени могут служить основой для интеграции, хотя тяга к новому объединению в ряде стран бывшего СССР явно присутствует. При этом отношение к распаду СССР и к возможному новому союзу существенно различается у респондентов с разным уровнем социального самочувствия. Среди неудовлетворенных сегодняшней жизнью более распространено позитивное отношение к интеграции - например, в Армении 
среди неудовлетворенных своей жизнью 55\% поддерживают идею объединения, среди удовлетворенных эта доля существенно ниже - 39\% [26, c. 18,19$]$.

Желаемое усиление гуманитарной составляющей интеграционных процессов на постсоветском пространстве, как это ни парадоксально, сталкивается с отсутствием весомой поддержки и заинтересованности в более тесной интеграции со стороны самой России. По данным опросов Левада-Центра, менее $20 \%$ россиян поддержали бы более тесное объединение всех республик бывшего СССР, например, по хорошо известному типу Европейского союза [27, с. 158].

\section{Социальные барьеры развития постсоветских государств}

Путь независимого развития постсоветских государств оказался в социальном плане более сложным и непредсказуемым, чем ожидалось накануне реформ. Надежды на то, что «...опыт международного сотрудничества государств с различными уровнями развития и социальным устройством даст возможность сравнительно легко и безболезненно реформировать постсоветское пространство в принципиально иной глобальной среде» [10, с. 16], не оправдались, и по прошествии вот уже почти трех десятилетий социальная ситуация в регионе остается напряженной.

Разрыв в уровнях ВВП на душу населения достигает более 8 раз, в уровне безработицы - более 5. При этом некоторые неожиданно выбивающиеся из общего ряда показатели (например, низкий уровень работающих бедных в Туркмении - 2,5\% от общей численности занятых) объясняются либо особенностями национальной статистики, либо наличием значительного теневого сектора, трудно поддающегося учету и, вследствие этого, существенно искажающего истинную картину.

Вместе с тем «сухие» социально-экономические показатели нивелируют существенные различия в интеграционных предпочтениях и, что не менее важно, в представлениях людей о социальной справедливости. На постсоветском пространстве взаимопереплетены три основные модели социальной справедливости: патерналистско-эгалитарная, или уравнительная (наиболее распространенная, унаследованная от социалистического этапа развития), социал-демократическая и либеральнорыночная - последняя в чистом виде встречается в СНГ лишь фрагментарно и, в отсутствие рыночных традиций, скорее всего, не имеет объективной почвы для своего развития. Эта особенность является серьезным препятствием для решения проблемы оптимального сочетания трудно совместимых друг с другом (в силу своеобразия постсоветского 
менталитета) критериев экономической эффективности и социальной справедливости.

Мировой опыт показывает, что эффективность социальноэкономических реформ напрямую зависит от качества социальной стратегии государства, отвечающей системе ценностей населения и специфике его менталитета. В работах Л.Евстигнеевой и Р.Евстигнеева показано, что в основе социальной энергии преобразований лежит прежде всего ментальность, которая «...становится важнейшей экономической категорией, определяющей уровень и состав социальной энергетики развития и экономического роста» [28, с. 179].

Вероятно, именно отсутствие достаточной социальной энергии, социального тонуса и стало одной из значимых причин промахов и неудач масштабной постсоветской социально-экономической трансформации. Как отмечает академик В.Полтерович, «в процессах социально-экономического развития важную роль играют такие элементы гражданской культуры, измеряемые с помощью опросов и экспериментов, как обобщенное доверие, толерантность, ценность свободы выбора, протяженность индивидуального планового горизонта и т.п.» $[6$, с. 20$]$.

На протяжении всего этапа постсоветского развития формируется глубокое разочарование людей, ощущение ими острой социальной несправедливости, выливающейся даже в требования пересмотреть итоги реформ и, в частности, отношений собственности. Только четверть россиян согласны, что реформы отвечают интересам большинства населения. При этом тех, кто считает, что путь, по которому сейчас идет страна, ведет в тупик, существенно выше среди тех, кто оценивает нынешнюю систему распределения частной собственности как несправедливую, чем среди тех, кто воспринимает это иначе (42 и 18\% соответственно) [29, с. 9]; [30, с. 48].

Социальное неравенство расценивается как чрезмерное и несправедливое всеми слоями россиян, независимо от их уровня жизни и динамики личного благополучия. Столь явное недовольство нарушениями социальной справедливости представляет собой важный фактор дестабилизации общества [31, с. 45], особенно в условиях незрелого гражданского общества, отсутствия многочисленного среднего класса, массовой бедности населения и колоссального социального расслоения. По данным опубликованного в 2017 г. первого Доклада о неравенстве в мире, с 1995 по 2015 г. доля верхней центили (1\% самых крупных состояний) в России возросла в 2 раза - с 22 до 43\% [32, р. 113].

После завершения острой фазы финансового кризиса 1998 г. материальное и социальное благополучие населения постсоветских государств улучшалось крайне медленно. На фоне экономического роста доля населения, живущего за чертой бедности, в начале 2000-х гг. ощутимо 
сокращалась (исключение составила только Армения), однако существенного снижения неравенства доходов так и не произошло (см. таблицу)

Таблица. Динамика уровня бедности и неравенства доходов

\begin{tabular}{|c|c|c|c|c|c|c|c|c|c|c|}
\hline & Уров & ь бедн & Ети & & & $\begin{array}{l}\text { Коэфф } \\
\text { Джини }\end{array}$ & циент & нераве & сства & оходов \\
\hline $\begin{array}{l}\text { Стран } \\
\text { Ы }\end{array}$ & 2001 & 2005 & 2010 & 2015 & 2017 & $\begin{array}{l}2000- \\
2001\end{array}$ & 2005 & 2010 & 2015 & 2017 \\
\hline $\begin{array}{l}\text { Азерб } \\
\text { айджа } \\
\text { н }\end{array}$ & 49,6 & $15,8^{4}$ & 9,1 & $6,0^{7}$ & 5,4 & 0,37 & 0,17 & $0,34^{5}$ & $\ldots$ & $\ldots$ \\
\hline $\begin{array}{l}\text { Арме } \\
\text { ния } \\
\end{array}$ & $\ldots$ & $27,6^{5}$ & 35,8 & 29,8 & $\ldots$ & 0,35 & 0,36 & 0,31 & 0,32 & $0,38^{8}$ \\
\hline $\begin{array}{l}\text { Белор } \\
\text { уссия }\end{array}$ & 28,9 & 12,7 & 5,2 & 5,1 & 5,9 & 0,31 & 0,28 & 0,28 & 0,27 & 0,27 \\
\hline $\begin{array}{l}\text { Казах } \\
\text { стан }\end{array}$ & 46,7 & 31,6 & 6,5 & 2,7 & 2,6 & 0,36 & 0,30 & 0,29 & 0,27 & 0,29 \\
\hline $\begin{array}{l}\text { Кирг } \\
\text { изия }\end{array}$ & $\ldots$ & $39,9^{3}$ & 33,7 & 32,1 & 25,6 & 0,31 & 0,38 & 0,30 & 0,29 & 0,39 \\
\hline $\begin{array}{l}\text { Молд } \\
\text { авия }\end{array}$ & 54,6 & 29,0 & 21,9 & 9,6 & $\ldots$ & 0,36 & 0,36 & 0,32 & 0,27 & 0,35 \\
\hline $\begin{array}{l}\text { Росси } \\
\text { я }\end{array}$ & $\ldots$ & 17,8 & 12,5 & 13,3 & 13,2 & 0,37 & 0,41 & 0,41 & 0,38 & 0,41 \\
\hline $\begin{array}{l}\text { Тадж } \\
\text { икист } \\
\text { ан }\end{array}$ & $\ldots$ & $\ldots$ & & 31,3 & $\ldots$ & $\ldots$ & $0,34^{2}$ & $0,31^{6}$ & 0,34 & \\
\hline $\begin{array}{l}\text { Турк } \\
\text { мения }\end{array}$ & $\ldots$ & $\ldots$ & $\ldots$ & $\cdots$ & $\ldots$ & $\ldots$ & $\ldots$ & $\ldots$ & $\ldots$ & $\ldots$ \\
\hline $\begin{array}{l}\text { Узбек } \\
\text { истан }\end{array}$ & $\ldots$ & $\ldots$ & 17,7 & $\ldots$ & $\ldots$ & 0,36 & $0,35^{1}$ & $\ldots$ & $\ldots$ & $\ldots$ \\
\hline $\begin{array}{l}\text { Укра } \\
\text { ина }\end{array}$ & & $12,7^{4}$ & 8,6 & 6,4 & 2,4 & $\ldots$ & 0,29 & 0,25 & 0,26 & 0,26 \\
\hline
\end{tabular}

${ }^{1} 2003$ г.; ${ }^{2} 2004$ г.; ${ }^{3} 2006$ г.; ${ }^{4} 2007$ г.; ${ }^{5} 2008$ г.; ${ }^{6} 2009$ г.; ${ }^{7} 2012$ г.; ${ }^{8} 2016$ г. Составлено по: [42, с. 12, 14], [46]

Официальная статистика далеко не всегда дает точное представление об уровнях реальной бедности и неравенства. Это связано как с определенными методологическими трудностями, так и с тем, что официально установленная черта бедности (величина прожиточного 
минимума) может быть значительно ниже уровня, необходимого для обеспечения устойчивого социально-экономического развития. По мнению экспертов, реальный уровень бедности в Казахстане существенно выше официальных данных (2,8\%) и достигает $10-20 \%$ общей численности населения [33, с. 112]. По данным Института демографии и социальных исследований НАН Украины, в 2014 г. к бедным относилась почти треть украинцев, а в первом полугодии 2015 г. этот показатель составил уже $53,5 \%$ и имел устойчивую тенденцию к росту [34].

Что касается истинных масштабов неравенства, то ситуация выглядит еще более запутанной. Так, по данным аналитиков компании Credit Suisse Group AG, в России официальное значение коэффициента Джини ${ }^{1}(0,41)$ занижено как минимум в два раза и составляет 0,84 [35, с. 24]. Р.Капелюшников, ссылаясь на исследование ученых-экономистов Ф.Новокмета, Т.Пикетти и Г.Цукмана, приводит цифру 0,55. По оценкам экспертов Всемирного банка, напротив, с 1998 по 2012 г. коэффициент Джини в России уменьшился почти на треть (с 0,49 до 0,33) [36].

Однако, независимо от расчетов и количественных показателей, неравенство воспринимается жителями постсоветских государств как необоснованное, что ставит под сомнение легитимность существующей экономической системы и оказывает значимое негативное влияние на уровень удовлетворенности жизнью. Его значения (по десятибалльной шкале оценок) варьируют от 4,3 баллов в Армении и Украине до 6,4 баллов в Узбекистане [37, р. 72-74].

Более того, в массовом сознании не прослеживается связь между собственными усилиями и ростом личного благосостояния. В середине 2018 г. более половины россиян считали, что «сколько ни работай, материального благополучия себе не обеспечишь», причем за последние три года их число увеличилось на 9 процентных пунктов [29, с. 60]. Отметим, что МВФ рассматривает проблему экономического неравенства как «окончательный, основной вызов нашего времени», который потенциально может привести к эффекту разорвавшейся бомбы в виде «негативных последствий для институциональных, политических, культурных и социальных систем...» [38, c. 125].

Ни в одном из постсоветских государств так и не сформировался полноценный средний класс, который мог бы сыграть роль социальнополитического стабилизатора процесса евразийской интеграции. В России,

1 Коэффициент Джини - показатель, характеризующий дифференциацию доходов населения в данной стране. Используется для оценки уровня экономического неравенства. Чем ближе его значение к единице, тем выше неравенство в распределении доходов. 
например, по мнению ряда исследователей, «...неартикулированность (“размытость”) социально-политических характеристик подтверждает точку зрения о недоформированности российского среднего класса, как особого массового социального субъекта. Это пока еще больше “класс в себе”, чем “класс для себя”» [39, с. 28].

Вместе с тем за годы реформ произошли явные качественные изменения в его составе - сейчас это уже «совсем не верхний квинтиль позднего советского общества (особенно интеллигенция), который поддержал рыночные и демократические реформы рубежа 80-90-х годов, а сложный “состав" из старой номенклатуры (захватившей часть активов), различных “теневых фигур” (вплоть до представителей преступного мира), коррумпированных чиновников и новых предпринимателей» [40, с. 54]. В Белоруссии также «...социальным итогом реформ стало не формирование процветающего среднего класса, а размывание ранее существовавших в стране средних слоев и обострившаяся поляризация общества» [41, с. 55].

Весьма чувствительным в социальном плане и болезненно воспринятым с точки зрения социальной справедливости стало повышение во многих странах СНГ возраста выхода на пенсию. На начало 2014 г. в Азербайджане он составил для мужчин 63 года, для женщин - 59,5 (с 2010 г. пенсионный возраст для женщин постепенно увеличивается до 60 лет), Казахстане, Киргизии и Таджикистане - соответственно 63 и 58 лет, Молдавии и Туркмении - 62 и 57 лет, на Украине - 60 лет и 56 лет (с октября 2011 г. пенсионный возраст для женщин постепенно увеличивается до 60 лет), в Армении и для мужчин, и женщин - 63 года. В Белоруссии и Узбекистане возраст выхода на пенсию пока сохранился на уровне 60 лет для мужчин и 55 лет для женщин, а в России с 2019 г. постепенно повышается до 60 лет для женщин и 65 лет для мужчин.

Возрастная структура населения стран СНГ за последние десятилетия меняется в сторону роста доли лиц старше 65 лет, что связано с увеличением во всех странах продолжительности жизни. В результате неизбежно усиливается давление на национальные пенсионные системы, которые в большинстве постсоветских государств и сейчас едва покрывают уровень минимальных потребностей пенсионеров. В конце 2017 г. минимальная пенсия по возрасту превышала размер прожиточного минимума пенсионера только в Белоруссии (в 1,5 раза) и Казахстане (в 2 раза). Значительно ниже прожиточного минимума был установлен размер минимальной пенсии по возрасту в Киргизии (в 2,5 раза), России и Молдове (в 1,5 раза) [42, с. 15].

Во всех странах СНГ размер пенсии по старости значительно ниже размера заработной платы. Их соотношение в 2017 г. в Армении, Молдавии и Таджикистане составляло в пределах 24-30\%, в России, Киргизии, Белоруссии и Украине - 31-40\%, в Казахстане и Азербайджане - 41-44\% 
[42, с. 23], [43]. Для сравнения: в Бразилии, Греции, Индии, Норвегии, Финляндии, Франции, Чешской Республике, Швейцарии, Швеции коэффициент замещения дохода (отношение пенсии к доходу работающего предпенсионного возраста) составляет более $50 \%$; в Словакии - более $60 \%$; Австрии, Венгрии, Дании, Исландии, Испании, Италии, Китае, Нидерландах - более $70 \%$ [44, с. 89].

Нарастающая интенсивность миграционных потоков в евразийском регионе, специфика социально-демографической ситуации, а также состояние национальных рынков труда неизбежно ставят на повестку дня вопросы координации пенсионных систем, создания общего пенсионного пространства. Важный шаг в этом направлении предпринят Россией и Белоруссией, подписавшими в начале 2006 г. «Договор между Республикой Беларусь и Российской Федерацией в области социального обеспечения». Согласно документу пенсия назначается на территории той страны, где человек выполнял какую-либо работу. При переезде выплата пенсии продолжается. Кроме того, возможна пропорциональная выплата пенсии двумя странами. Трудовые мигранты для сохранения стажа могут добровольно отчислять взносы в пенсионный фонд страны, гражданами которой они являются [45, с. 6,17$]$.

Тернистый путь евразийской интеграции, сопровождаемый кардинальным переустройством социальных основ жизни общества, позволяет предположить, что дальнейшее продвижение и углубление интеграционных процессов едва ли возможно без учета вопросов социальной справедливости, прочности и качества человеческого капитала, который становится особо значимым ресурсом в эпоху широкомасштабной цифровизации экономики и от которого, в конечном счете, зависит судьба единого евразийского пространства.

\section{СПИСОК ЛИТЕРАТУРЫ}

1.Евразия в поисках идентичности (под ред. С.П.Глинкиной, Л.3.Зевина). 2011. СПб.: Нестор-История, 256 с.

2. Вардомский Л.Б. 2017. Постсоветская интеграция и экономический рост нового приграничья России в 2005-2015 гг. - Пространственная экономика, №4, с. 22-40. 
3.Евразийский интеграционньй проект: эффректы и проблемы реализации (отв. ред. С.П. Глинкина). 2013. М.: Институт экономики РАН, $92 \mathrm{c}$.

4. Винокуров Е.Ю. 2015. Опыт региональных интеграционных объединений: уроки для ЕАЭС - Евразийская экономическая интеграџия, №2, с. 94-97.

5. Бородачёва Е.М., Щекотуров А.В. 2017. Евразийский медиаиндекс. II квартал 2017 года. Москва, Минск: Институт социологии НАН Беларуси, Центр изучения перспектив интеграции, 46 с.

6. Полтерович В.М. 2018. К общей теории социально-экономического развития. Часть I. География, институты или культура? - Bonpocbl экономики, №11, с. 5-26.

7. Интеграциинный барометр ЕАБР - 2014. Аналитическое резюме (рук. проекта В.С. Перебоев). 2014. СПб: ЦИИ ЕАБР, 32 с.

8. Интеграционный барометр ЕАБР - 2017 (рук. проекта В.С. Перебоев). 2017. СПб.: ЦИИ ЕАБР, 108 с.

9. Крылов А., Арешев А. 2014. Евразийская интеграция: проблемы и потенциал развития - Россия и новые государства Евразии, №4 (25), с. 23-33.

10. Зевин Л.3. 2015. О некоторых проблемах экономического пространства Евразии XXI века. Научный доклад. М.: Институт экономики $\mathrm{PAH}, 40 \mathrm{c}$.

11. Вардомский Л.Б. 2018. Состояние и перспективы взаимных экономических отношений Беларуси, России и Украины в контексте их идентичности. - Россия и современный мир, №3 (100), с. 103-117.

12. Косикова Л.С. 2010. Социальные и культурные факторы региональной интеграции: опыт ЕС и СНГ. - Социальные факторы постсоветской интеграции (отв. ред. Т.В. Соколова). М.: ИЭ РАН, 242 с.

13. Будущее Беларуси. Взгляд независимых экспертов (под ред. О. Манаева). 2012. Санкт-Петербург: «Невский простор», 534 с.

14. Южный Кавказ: тенденции и проблемь развития (1992-2008 годы) (отв. ред. и рук. авт. кол. В.А.Гусейнов). 2008. М.: Красная звезда, 392 c.

15. Бабаян Д. 2015. Азербайджано-карабахский конфликт: этнополитика и безопасность. - Россия и новые государства Евразии, №2 (27), c. 32-41.

16. Caucasus Barometer regional dataset / The Caucasus Research Resource Centers (CRRC). URL: https://caucasusbarometer.org/en/cb2013/MAINFRN (дата обращения 02.05.2019); https://caucasusbarometer.org/en/cb2017/MAINFRN (дата обращения 02.05.2019). 
17. Вардомский Л.Б., Пылин А.Г., Соколова Т.В. 2014. Страньл Южного Кавказа: особенности развития и регионального взаимодействия. М.: Институт экономики РАН, 60 с.

18. Ушкалова Д.И., Головнин М.Ю. 2011. Теоретические подходы $\kappa$ исследованию международной экономической интеграции. М.: Институт экономики РАН, 44 с.

19. Соџиокультурные особенности российской модернизаџии: материальь круглого стола. 2009. М.: Экон-Информ, 152 с.

20. Тренин Д. Контурная карта российской геополитики: возможная стратегия Москвы в Большой Евразии. URL: https://carnegie.ru/2019/02/11/ru-pub-78328 (дата обращения 15.03.2019).

21. Восприятие молодежью новых независимых государств истории советского и постсоветского периодов. Аналитический отчет по исследовательскому проекту «Евразийский монитор». URL: http://eurasiamonitor.org/uploads/s/g/f/f/gffzlsnrpxne/file/o9GDpzJR.pdf (дата обращения 02.05.2019).

22. Рыбаковский Л.Л. Миграционный потенциал новых независимых государств и условия его привлечения в Россию. Научный доклад. http://ecsocman.hse.ru/data/2011/09/02/1267440637/Rybakovsky.pdf _дата обращения 02.05.2019).

23. Выхованец О.Д., Прохорова А.В., Савинкова Ю.К. и др. 2014. Трансформащия идентичности трудовых мигрантов как одна из составляющих становления гражданского общества в России. М.: Фонд «Наследие Евразии», 144 с.

24. Молодежь в Содружестве Независимых Государств: статистический портрет. 2018. М.: Статкомитет СНГ, ЮНФПА, 175 с.

25. Центральная Азия 2027: меняющийся стратегический ландшафт. Вероятные сиенарии на десять лет вперед. 2017. Астана: Библиотека Первого Президента РК - Елбасы, 122 с.

26. Общественное мнение о распаде СССР в странах постсоветского мира. 1991-2016. Проект «Евразийский монитор». 2017. 20 c.

27. Общественное мнение - 2014. М.: Левада-Центр, 234 с.

28. Евстигнеева Л.П., Евстигнеев Р.Н. 2011. Новые грани ментальности: синергетический подход. М.: ЛЕНАНД, 192 с.

29. Левашов В. К., Афанасьев В. А., Новоженина О. П. и др. 2018. Состояние гражданского общества в России. XLVII этап соииологического мониторинга «Как живешь Россия?», май 2018 г. / Под общ. ред. В. К. Левашова. М.: Изд-во «Экон-Информ», 108 с. 
30. Мареева С. В., Тихонова Н. Е. 2016. Бедность и социальные неравенства в России в общественном сознании. - Мир России. Т. 25, № 2, с. 37-67.

31. Немировский В. Г. 2017. Представления о справедливости в контексте сословной структуры современного российского общества. Социологические исследования, № 9, с. 40-47.

32. World Inequality Report-2018. World Inequality Lab. 2017. 296 p.

33. Алиев Т. 2015. Бедность в Казахстане. - Мировая экономика и международные отношения, №12, с. 105-116.

34. Демоскоn Weekly. 2016. № 675-676, 22 февраля - 6 марта. URL: http://demoscope.ru/weekly/2016/0675/panorm01.php\#8 (дата обращения 02.05.2019).

35. Ирсетская Е.А., Китайцева О.В. 2015. Социальная справедливость как платформа реализации жизненных устремлений россиян. - Мониторинг общественного мнения: экономические и социальные перемены, № 6, с. 19-31.

36. Капелюшников Р. 2019. Как считать неравенство - Ведомости, 05.03.

37. Human Development Indices and Indicators: 2018 Statistical Update. N.-Y.: United Nations Development Programme, 112 p.

38. Риччери М. 2017. Как спасти социальность рыночной экономики. - Мир перемен, №1, с. 124-138.

39. Латов Ю. В., Петухов В. В. 2017. Выполняют ли российские средние слои роль социального стабилизатора? - Мониторинг общественного мнения, № 6 (142), с. 1-30.

40. Григорьев Л., Курдин А. 2016. Нерешенный вопрос легитимности частной собственности в России. - Вопросы экономики, №1, с. 36-62.

41. Соколова Г.Н. 2011. Место и роль среднего класса в стратификационной конфигурации белорусского общества. Социологический альманах (Институт социологии НАН Беларуси), № 2, с. 55-68.

42. Мониторинг показателей качества жизни населения в странах Содружества Независимых Государств 2014-2017. 2018. М.: Межгосударственный статистический комитет СНГ, 69 с.

43. Заработная плата в странах СНГ. URL: http://www.cisstat.ru/rus/macro/zp-1.pdf (дата обращения 02.05.2019)

44. О пенсионном обеспечении в странах Содружества. 2014. Статистика СНГ (Статистический бюллетень), №12 (543), с. 81-96.

45. Карабчук Т.С., Соболева Н.Э., Перебоев В.С. 2014. Введение общего пенсионного пространства в странах Евразийского экономического 
союза: насколько это важно и каковы последствия? - Евразийская экономическая интеграция, № 3, с. 5-24.

46. The World Bank (Data Sets). URL: http://data.worldbank.org/indicator/SI.POV.GINI (дата обращения 15.03.2019); http://data.worldbank.org/indicator/SL.UEM.TOTL.ZS (дата обращения 15.03.2019); http://data.worldbank.org/indicator/SI.POV.NAHC/countries (дата обращения 15.03.2019) 